Research Article

\title{
Cavity-Backed Angled-Dipole Antennas for Millimeter-Wave Wireless Applications
}

\author{
Son Xuat Ta and Ikmo Park \\ Department of Electrical and Computer Engineering, Ajou University, 206 Worldcup-ro, Yeongtong-gu, Suwon 16499, Republic of Korea \\ Correspondence should be addressed to Ikmo Park; ipark@ajou.ac.kr
}

Received 14 March 2016; Accepted 3 May 2016

Academic Editor: Claudio Gennarelli

Copyright (C) 2016 S. X. Ta and I. Park. This is an open access article distributed under the Creative Commons Attribution License, which permits unrestricted use, distribution, and reproduction in any medium, provided the original work is properly cited.

\begin{abstract}
A cavity-backed angled-dipole antenna is proposed for millimeter-wave wireless applications. The angled-dipole radiator is built on both sides of an RT/Duroid 5880 substrate $\left(\varepsilon_{r}=2.2\right)$ and fed by a parallel-plate transmission line. The cavity-backed reflector is utilized to improve the radiation characteristics of the angled dipole, such as gain, back-radiation, symmetric pattern, and similar $3 \mathrm{~dB}$ beamwidth in the $E$ - and $H$-planes. The design, with a cavity aperture of $0.5 \lambda_{28-\mathrm{GHz}} \times 0.5 \lambda_{28-\mathrm{GHz}}$, results in a $\left|S_{11}\right|<-10 \mathrm{~dB}$ bandwidth of $26.7-30.6 \mathrm{GHz}$, a gain of 6.6-8.0 dB, and a similar $3 \mathrm{~dB}$ beamwidth of approximately $70^{\circ}$ for both the $E$ - and $H$-planes. Eight-element linear arrays with the proposed antenna having a center-to-center spacing of $5.6 \mathrm{~mm}\left(0.52 \lambda_{28-\mathrm{GHz}}\right)$ are characterized, fabricated, and measured. By applying nonuniform power distribution across excitations, the array achieves a scan angle up to $40^{\circ}$ and a sidelobe level below $-15 \mathrm{~dB}$.
\end{abstract}

\section{Introduction}

Recently, the fourth-generation (4G) long-term evolution (LTE) mobile communication technology has been successfully implemented in many parts of the world. With a carrier frequency spectrum ranging from $700 \mathrm{MHz}$ to $2.6 \mathrm{GHz}$, current cellular providers are attempting to deliver high-quality, low-latency video and multimedia applications for wireless devices [1]. Along with the rapid increase in smartphone use and mobile data growth, the ability to increase the data rates is the main challenge for wireless service providers. Several signal-processing techniques have been successfully applied to $4 \mathrm{G}$ cellular communications. However, because of the global bandwidth shortage, there have not been significant advances with respect to increased data rates. To overcome this problem, the future fifth-generation (5G) of wireless cellular networks is expected to better utilize the millimeterwave bands, where the available bandwidths are much wider than those currently being used [1]. At current cell densities, millimeter-wave wireless cellular communication can offer more than an order of magnitude increase in capacity over current state-of-the-art 4G cellular networks [2]. To achieve these gains, millimeter-wave cellular systems require highly directional and adaptive transmitters as well as directional isolation between links. To address these challenges, beamforming has been proposed as an enabling technology [3, 4] for $5 \mathrm{G}$ wireless cellular communication. It is well known that active-phased arrays represent the traditional beamforming technology; in phased array systems, the high-power generation for transmitting and low-noise amplification on the receiving end are distributed, as is the phase control at each radiating element $[5,6]$. Accordingly, designing an antenna for the millimeter-wave phased array could be an important step on the road to realize $5 \mathrm{G}$ wireless cellular communication systems.

Planar printed antennas have gained interest for millimeter-wave phased array applications because of their wide bandwidth, low cost, ease of fabrication, and potential for high-efficiency operation [7-10]. A printed-dipole antenna using a microstrip-fed coplanar strip T-junction was designed for a Ka-band phased array [7]. Another printeddipole antenna with two arms placed on both sides of a substrate is fed by a coaxial line without balun [8]. To achieve the desired broadside radiation, these two antennas employed a large metallic plate acting as a reflector. An angled-dipole antenna with an endfire gain of $2.5 \mathrm{~dB}$ was developed for phased array applications in the $22-24 \mathrm{GHz}$ band [9]. Although the angled dipole yielded a beamwidth 


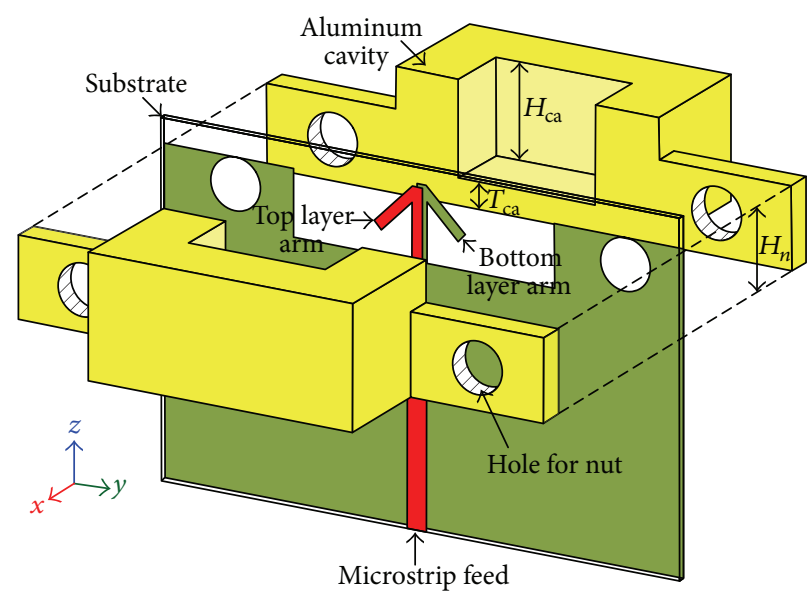

(a)

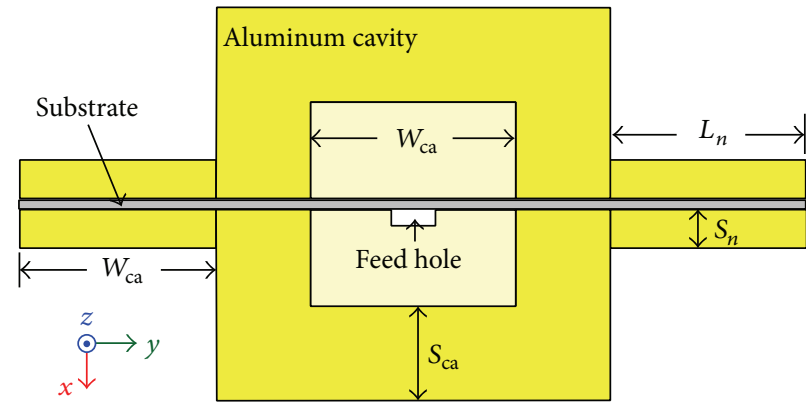

(b)

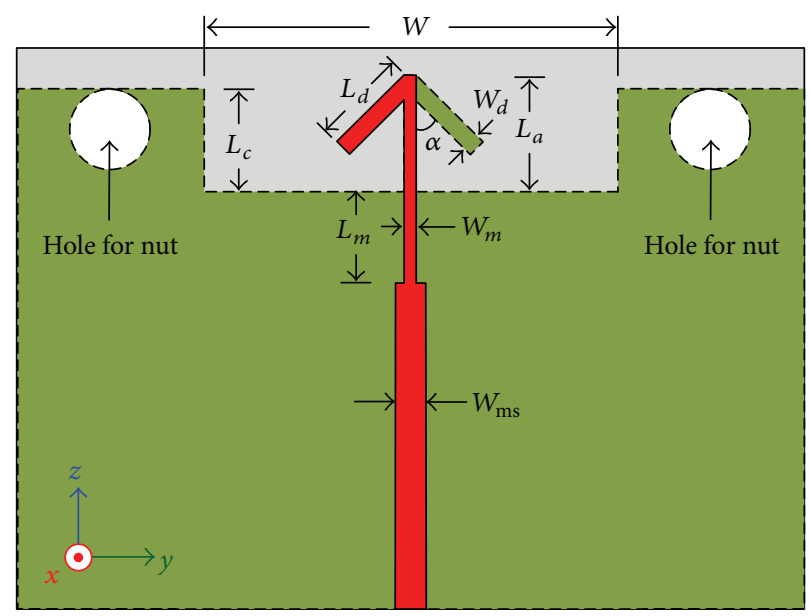

(c)

FIGURE 1: Geometry of the cavity-backed angled-dipole antenna: (a) perspective view, (b) top view, and (c) angled-dipole radiator.

improvement for the $E$-plane pattern, the beamwidth is significantly different for the radiation patterns in the $E$ and $H$-planes. The beamwidth difference of the angled-dipole antenna can be mitigated by using a corrugated ground plane [9], but this method is accompanied by a significant reduction in impedance bandwidth. In [10], another angled-dipole antenna employed a planar metallic reflector to improve the antenna gain. However, its pattern profile is not symmetric due to the asymmetry of the design.

In this paper, a composite cavity-backed angled-dipole antenna [11] and its arrays are developed for the millimeterwave band wireless applications, especially the antenna sectors in the $5 \mathrm{G}$ wireless cellular communication systems. The cavity is used to improve the radiation characteristics of the angled-dipole in terms of gain, symmetric pattern, and similar beamwidth in the $E$ - and $H$-planes. The applicability of the proposed antenna in the phased arrays is demonstrated by its eight-element linear arrays. To achieve the low-sidelobe levels, nonuniform power distributions are used for excitation of the arrays. Scanning performances of the arrays are first examined using the CST Microwave Studio and then confirmed by experimental tests of several fixed-scan angle arrays.

\section{Single Element}

2.1. Antenna Geometry. Figure 1 shows the geometry of the proposed antenna, which is composed of an aluminum cavity and an angled dipole. The cavity is divided into two parts for ease of installation, that is, the front and rear parts. There is a hole in the front part of the cavity for the feeding line of the antenna. The angled dipole that is the primary radiation elements of the proposed design is printed on an RT/Duroid 5880 substrate with a permittivity of 2.2 , a loss tangent of 0.0009 , and a thickness of $0.254 \mathrm{~mm}$. The radiator consists of two identical $45^{\circ}$ angled arms, one on the top side and the other on the bottom side of the substrate. The antenna is designed to match to a microstrip line of width $W_{\mathrm{ms}}=$ $0.74 \mathrm{~mm}$ (characteristic impedance of $50 \Omega$ ). The antenna is fed by a microstrip feed line that transits to a parallelplate transmission line for the angled dipole. The radiator is clamped between two parts of the cavity. The antenna, 


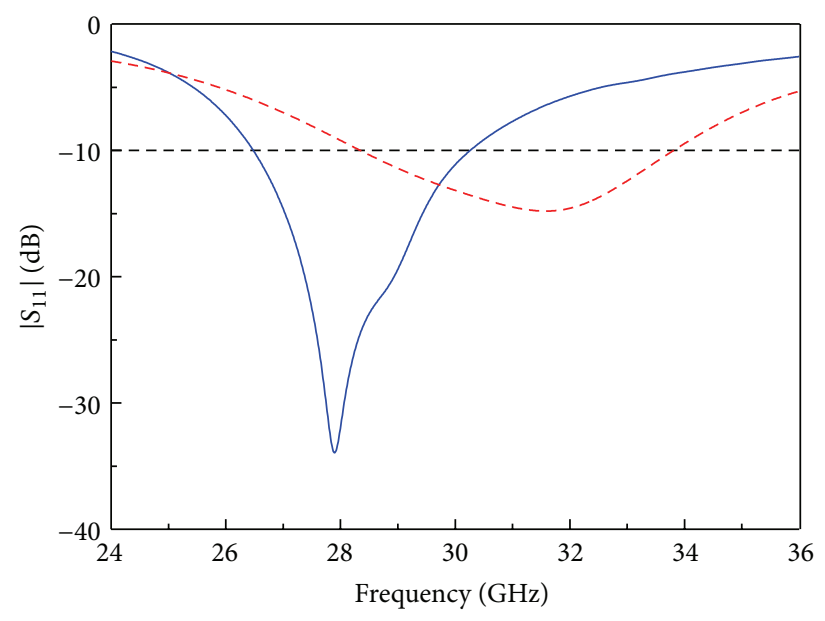

_ With cavity
- - W/o cavity

(a)

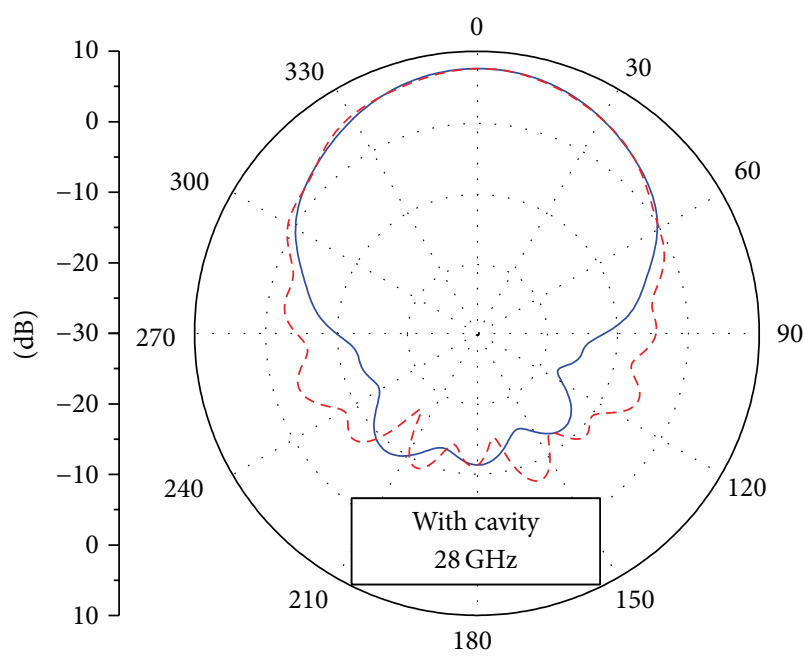

- E-plane

- - H-plane

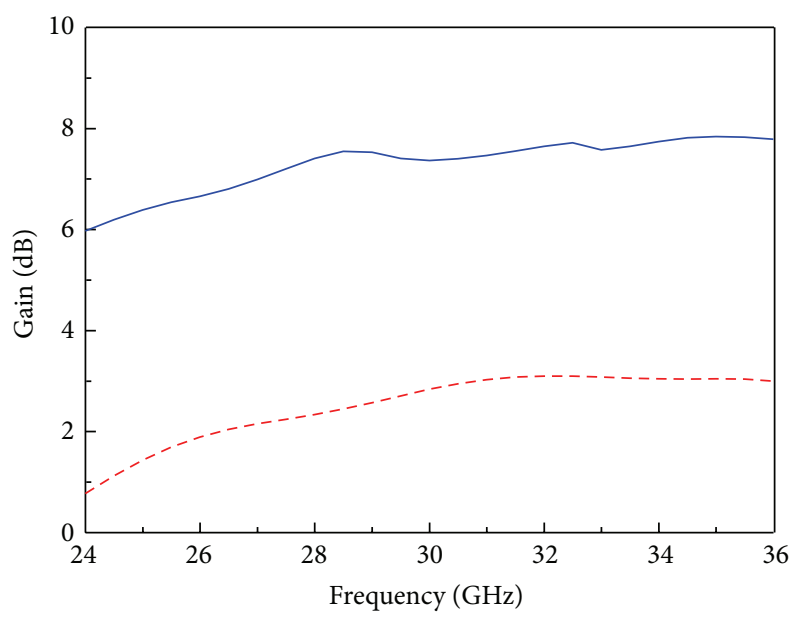

- With cavity

- - W/o cavity

(b)

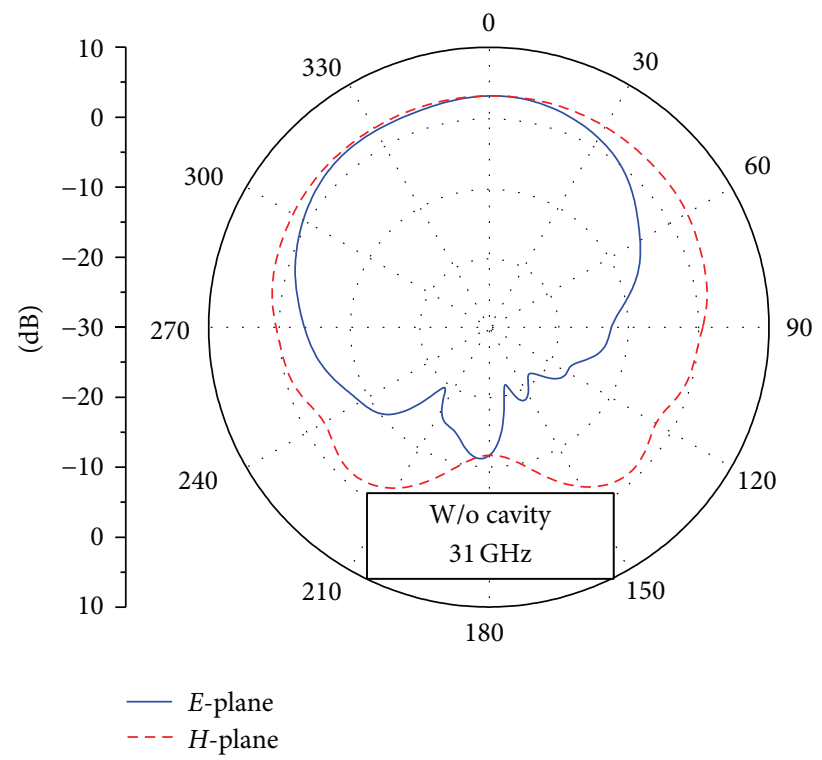

(c)

FIGURE 2: Performance comparison for the angled-dipole antennas with and without cavity: (a) $\left|S_{11}\right|$, (b) gain, and (c) radiation patterns.

with a fixed-cavity aperture of $0.5 \lambda_{28-\mathrm{GHz}} \times 0.5 \lambda_{28-\mathrm{GHz}}$, was optimized in terms of good impedance matching and high gain at $28 \mathrm{GHz}$ using CST Microwave Studio. The parameters for the final design were as follows: $H_{\mathrm{ca}}=3.5 \mathrm{~mm}, T_{\mathrm{ca}}=$ $1.0 \mathrm{~mm}, H_{n}=3.0 \mathrm{~mm}, S_{\text {ca }}=2.4 \mathrm{~mm}, W_{\mathrm{ca}}=5.2 \mathrm{~mm}$, $L_{n}=5.0 \mathrm{~mm}, W_{\mathrm{ms}}=0.74 \mathrm{~mm}, W_{m}=0.4 \mathrm{~mm}, W=10 \mathrm{~mm}$, $L_{c}=2.0 \mathrm{~mm}, L_{m}=2.0 \mathrm{~mm}, L_{a}=2.8 \mathrm{~mm}, L_{d}=2.1 \mathrm{~mm}$, $W_{d}=0.4 \mathrm{~mm}$, and $\alpha=45^{\circ}$.

2.2. Cavity-Backed Reflector. As mentioned in [9], the angled-dipole yields a wider $E$-plane pattern, a higher frontto-back ratio, and a more compact size as well as a lower mutual coupling between two elements compared to the conventional dipole. This antenna, however, yielded a small gain $(<3 \mathrm{~dB})$ and a significant difference in beamwidths for the radiation patterns in the $E$ - and $H$-planes. To improve the radiation characteristic in terms of gain and balance profile in the $E$ - and $H$-plane patterns, the angled dipole is backed by a metallic cavity [12]. Figure 2 shows a performance comparison for the angled dipole with and without a cavity. As shown in Figure 2(a), the angled dipole without cavity yielded a $\left|S_{11}\right|<-10 \mathrm{~dB}$ bandwidth of $28.3-33.8 \mathrm{GHz}$, whereas the operational bandwidth of the design with a cavity shifted toward the lower frequency; its $\left|S_{11}\right|<-10 \mathrm{~dB}$ bandwidth was $26.5-30.2 \mathrm{GHz}$. Because of the presence of the cavity-backed reflector, the gain of the angled-dipole antenna was significantly increased (Figure 2(b)); the original design yielded a gain of $2.3-3.1 \mathrm{~dB}$ within the impedance matching 

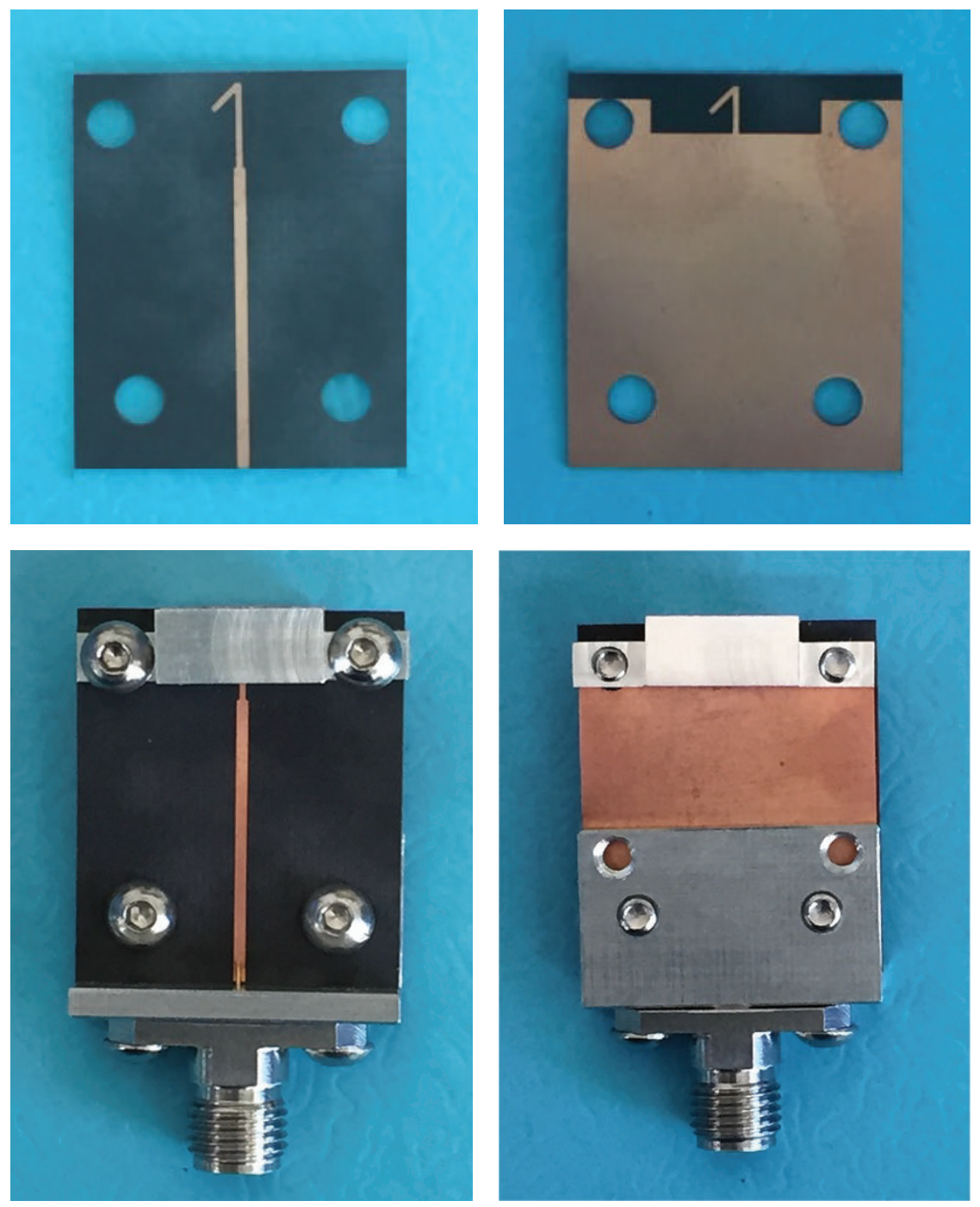

FIGURE 3: Fabricated sample of the cavity-backed angled-dipole antenna including jig and $2.92 \mathrm{~mm}$ SMA connector.

bandwidth, whereas the proposed design yielded a gain of $6.8-7.5 \mathrm{~dB}$. The gain enhancement is approximately $4.5 \mathrm{~dB}$, while the $H$-plane pattern narrowed and the back radiation reduced (Figure 2(c)). This improvement is due to the different radiation mechanism of the two configurations. For the angled-dipole antenna without cavity, the truncated ground plane acts as a reflector, and, consequently, the ground plane size and the position and geometry of the dipole are crucial factors in determining the beamwidth and gain of the antenna. For the proposed configuration, the radiation profiles are mainly determined to a large extent by the size of the cavity aperture; that is, the dipole has less effect than the cavity to assure good broadside radiation pattern. Because the two arms of the original design were placed on different sides of the substrate, the $E$-plane pattern was not very symmetric. This was also addressed by using the cavity; the proposed antenna yielded a symmetric profile and a similar $3 \mathrm{~dB}$ beamwidth for both the $E$ - and $H$-planes. With this feature, the proposed antenna can work in the twodimensional array environments stably.
2.3. Measurements. To verify the features, a composite cavitybacked angled-dipole antenna was fabricated and measured. The cavity was made of an aluminum alloy. The radiator was realized by standard wet-etching technology on both sides of a Rogers RT/Duroid 5880 sheet with a copper thickness of $17 \mu \mathrm{m}$. Figure 3 shows photographs of the fabricated antenna, including an aluminum jig and a GigaLane $2.92 \mathrm{~mm}$ SMA connector (not included in the simulations). The components of the fabricated antenna were fastened by nuts of diameter $2.5 \mathrm{~mm}$. The measurements of the prototype were carried out at the Electromagnetic Wave Technology Institute, Seoul, Korea. An Agilent N8364B network analyzer and two calibration kits (Agilent 85052D and 85056K) were used to measure the input impedance of the antenna. Another Agilent E8362C network analyzer and a full anechoic chamber with dimensions $9.0 \mathrm{~m}(L) \times 6.0 \mathrm{~m}(W) \times 4.8 \mathrm{~m}(H)$ were used for radiation pattern measurements.

Figure 4(a) shows a comparison of the measured and simulated $\left|S_{11}\right|$ values for the printed-dipole antenna. For $\left|S_{11}\right|<-10 \mathrm{~dB}$, the measured impedance bandwidth 


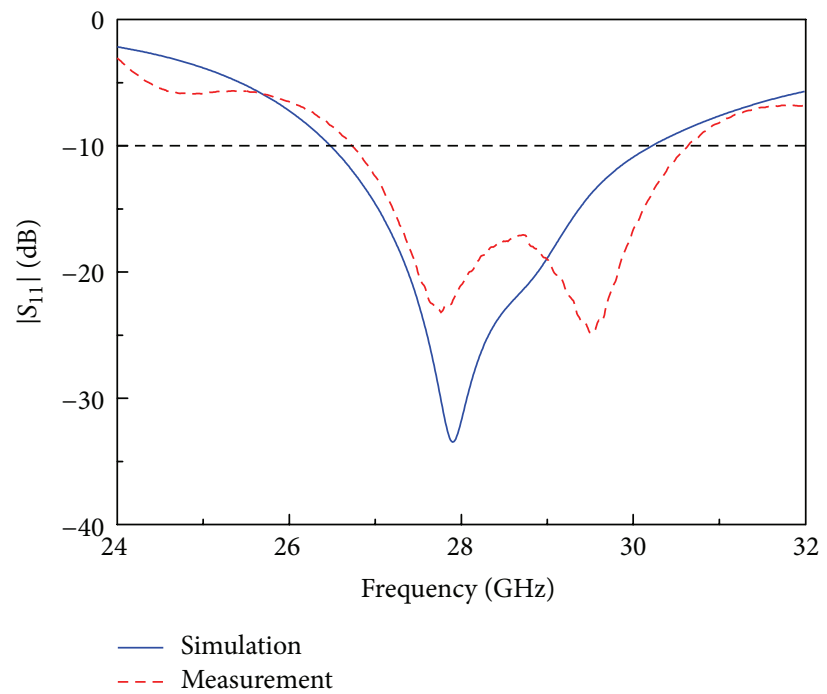

(a)
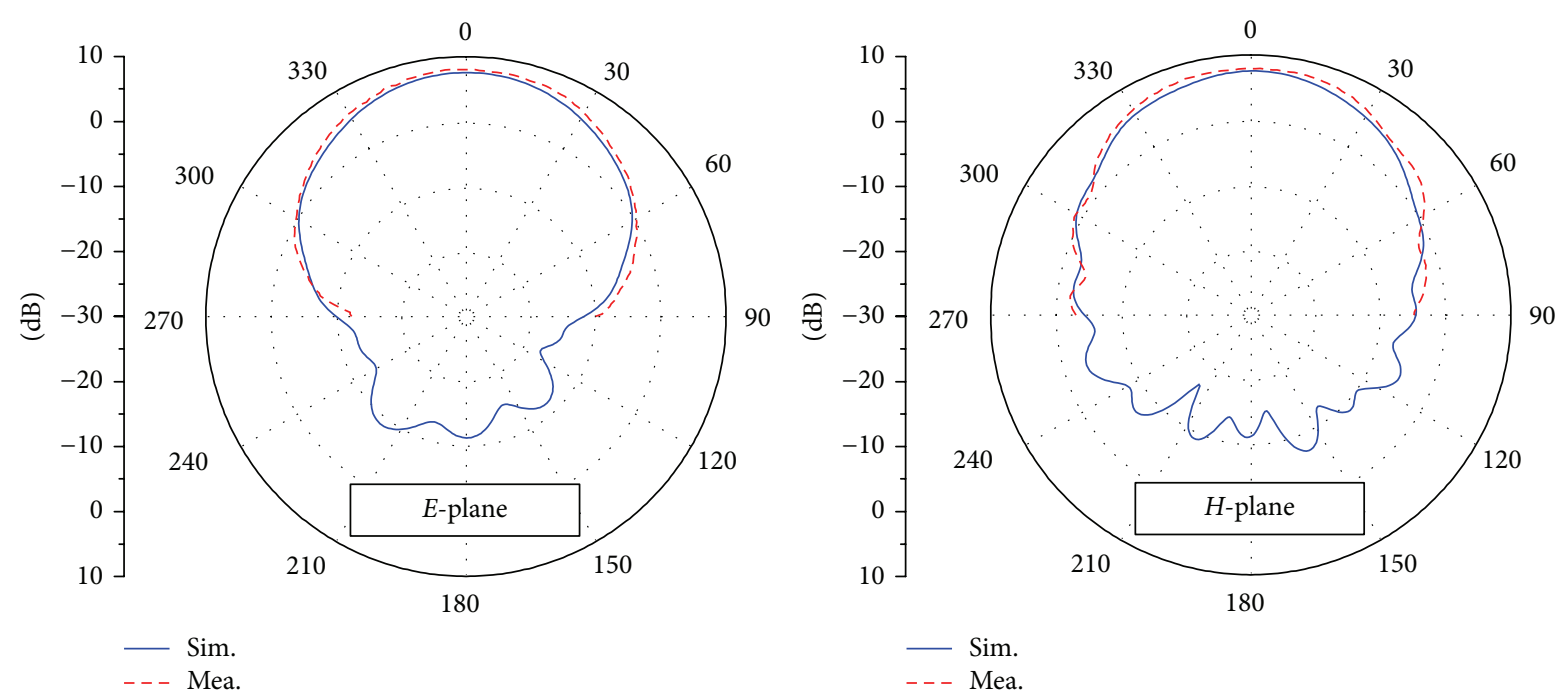

(b)

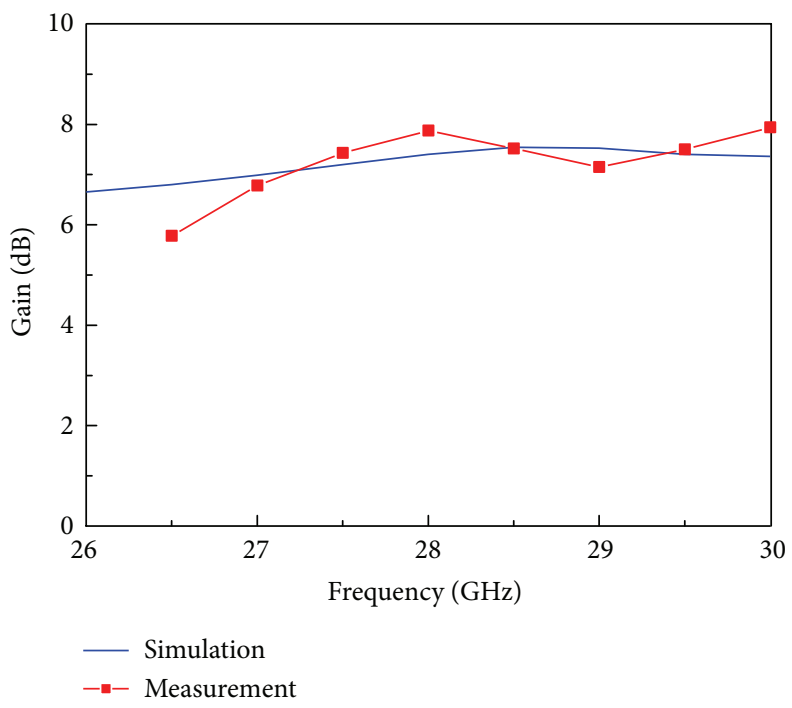

(c)

FIgURE 4: Measured and simulated (a) $\left|S_{11}\right|$, (b) $28 \mathrm{GHz}$ gain pattern, and (c) broadside gain values. 

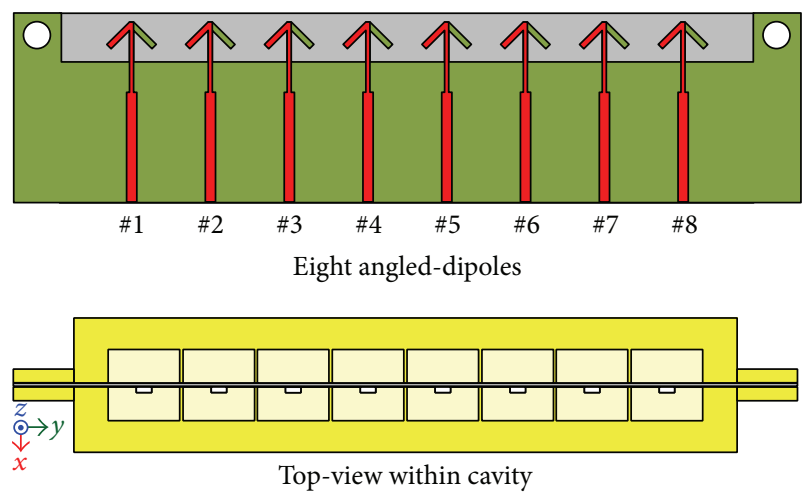

(a)

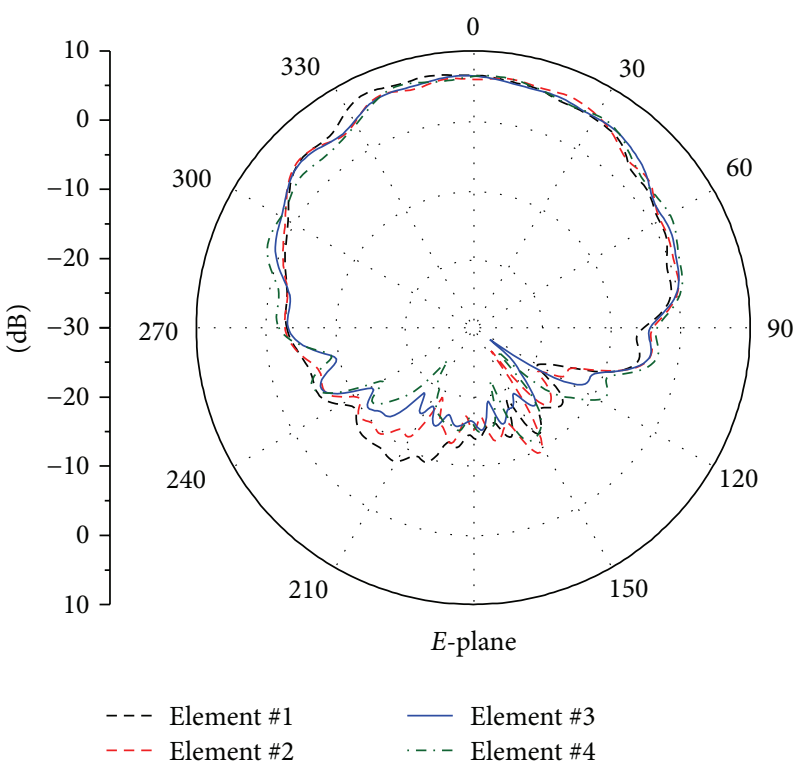

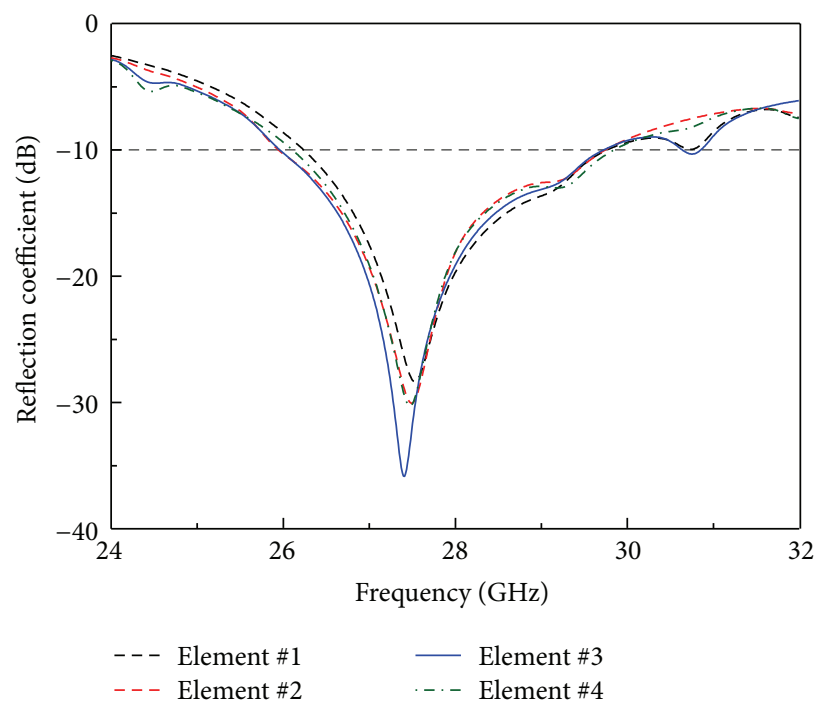

(b)

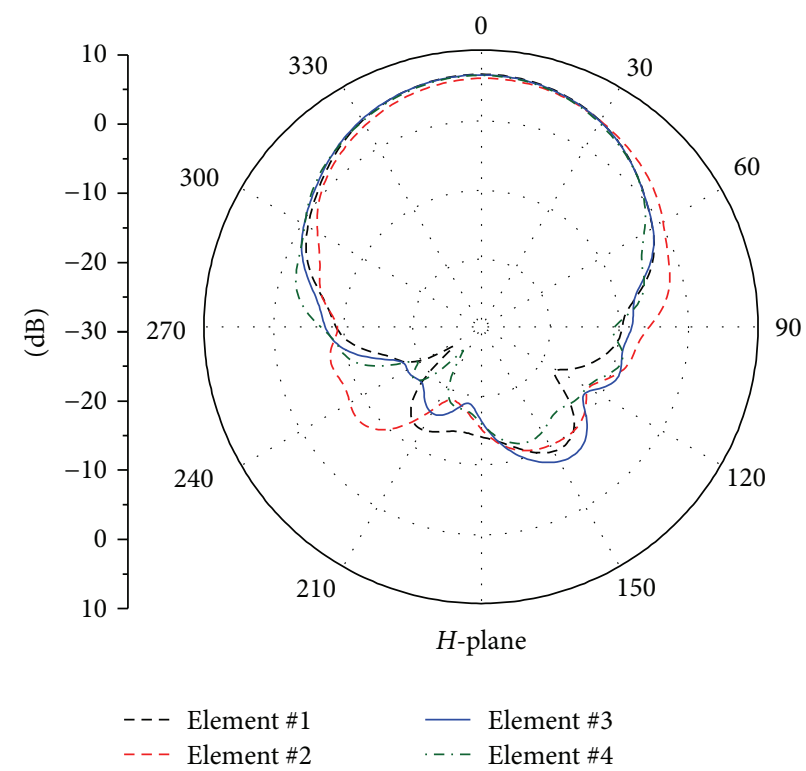

(c)

FiguRE 5: (a) Geometry of an eight-element linear array with the proposed antenna and a center-to-center spacing of $5.6 \mathrm{~mm}$. Simulated (b) $\left|S_{11}\right|$ values and (c) active patterns for the different elements.

was $26.7-30.6 \mathrm{GHz}$, whereas the simulated value was $26.5-$ 30.2 GHz. The slight difference between the measurement and simulation could be attributed to misalignment between the two parts of the cavity and the effects of the jig and SMA connector. Figure 4(b) shows a comparison of the simulated and measured gain patterns of the fabricated antenna at $28 \mathrm{GHz}$ and shows a good agreement between the two. The antenna resulted in a good broadside radiation pattern with a symmetric profile and similar beamwidth in both the $E$ and $H$-planes. The simulations resulted in a gain of $7.5 \mathrm{~dB}$, a front-to-back ratio of $18.5 \mathrm{~dB}$, and half-power beamwidths (HPBWs) of approximately $70^{\circ}$ in both the $E$ - and $H$ planes. The front-radiation measurements yielded a gain of $8.0 \mathrm{~dB}$ and HPBWs of $72^{\circ}$ and $69^{\circ}$ in the $E$ - and $H$-planes, respectively. Figure 4(c) shows a comparison of the measured and simulated broadside gain for the fabricated antenna. Within the operational bandwidth, the measured gain was $6.6-8.0 \mathrm{~dB}$, whereas the simulated value was $6.8-7.5 \mathrm{~dB}$. The measured gain was slightly different from the simulated value. This difference could be attributed to the tolerances of the amplifiers in the measurement setup. The radiation efficiency of the antenna was not measured, but the simulations resulted in a high value of $>93 \%$ within the operation bandwidth.

\section{Antenna Arrays}

3.1. Active Patterns. An eight-element array with the cavitybacked angled-dipole antenna having a center-to-center spacing of $5.6 \mathrm{~mm}$ (Figure $5(\mathrm{a})$ ) is used to examine the active patterns of different elements [13]. For the examination, 

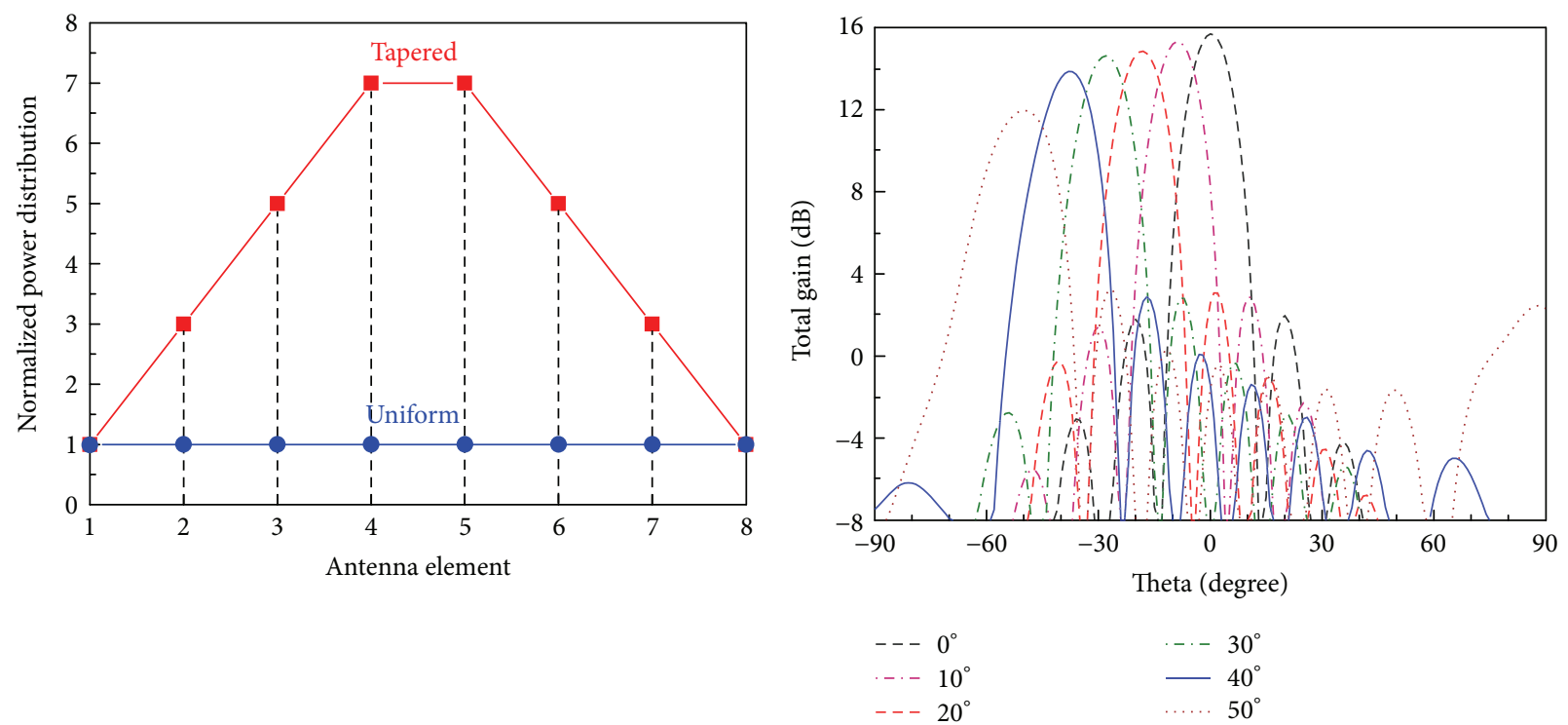

(a)

(b)

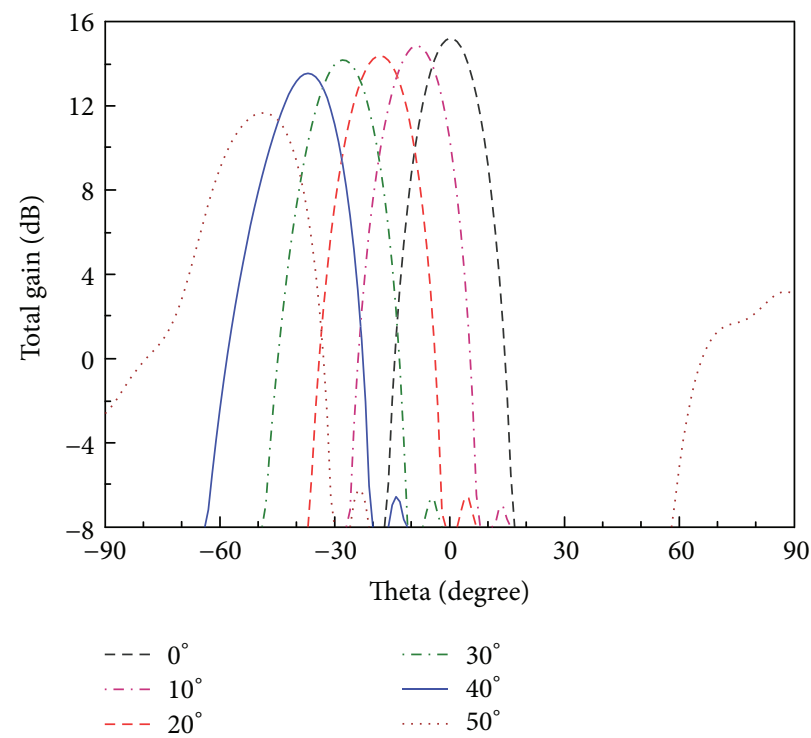

(c)

FiguRE 6: (a) Different power distributions for excitation of the eight-element linear array. Simulated scanning performance in $E$-plane for the array at $28 \mathrm{GHz}$ with (b) uniform and (c) tapered excitations.

each element from \#1 to \#8 was excited one by one, while other elements were terminated with $50 \Omega$. Their reflection coefficients and $28 \mathrm{GHz}$ radiation patterns are shown in Figures 5(b) and 5(c), respectively. Because of the symmetric configuration, the results for elements \#5-\#8 are completely the same as those of the elements \#4-\#1, respectively and therefore are not shown. It is observed that the impedance bandwidth and radiation characteristics of all elements in the linear array environment are very close to those of the single element due to the low mutual coupling $(<-16 \mathrm{~dB})$.

3.2. Eight-Element Arrays Using Tapered Excitation. In phased array applications, low-sidelobe antennas are desired to counter active interference and achieve better performance [14]. In order to synthesize low-sidelobe phased arrays with the cavity-backed angled-dipole antennas, a tapered power distribution (Figure 6(a)) was developed and realized across the excitation of the eight-element linear array with a centerto-center spacing of $5.6 \mathrm{~mm}$. Figures $6(\mathrm{~b})$ and $6(\mathrm{c})$ show the scanning performance of the array at $28 \mathrm{GHz}$ for the uniform and tapered power-distribution excitations, respectively. The patterns were calculated using the array-factor function of CST Microwave Studio. Grating-lobe-free beam scanning up to a maximum of $40^{\circ}$ was achieved for both excitations. The array with tapered excitation yielded significantly lower sidelobe level and broader beam pattern compared 
TABLE 1: Gain of the eight-element linear arrays.

\begin{tabular}{lccr}
\hline & Theory & Simulation & Realization \\
& & $14.0 \mathrm{~dB}$ & Measurement \\
\hline $0^{\circ}$ scan & $15.2 \mathrm{~dB}$ & $11.8 \mathrm{~dB}$ & $11.7 \mathrm{~dB}$ \\
$40^{\circ}$ scan & $13.5 \mathrm{~dB}$ & $\mathrm{~dB}$ \\
\hline
\end{tabular}

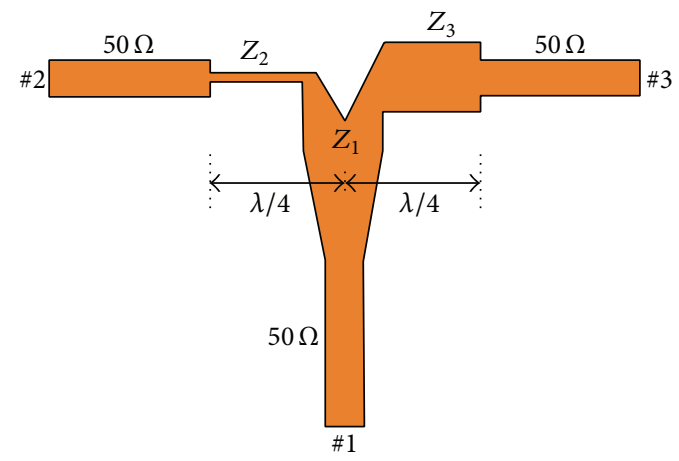

FIgURE 7: Geometry of unequal T-junction power divider.

to the uniform-excitation case. The broader beamwidth is accompanied by the lower gain. As show in Figure 6(b), the array excited by uniform power distribution yielded sidelobe levels below $-11 \mathrm{~dB}$, HPBWs of $12^{\circ}-14.5^{\circ}$, and gain of $13.8-$ $15.7 \mathrm{~dB}$ for all scanning angles. As show in Figure 6(c), the array with tapered distribution yielded sidelobe levels below $-20 \mathrm{~dB}$, HPBWs of $14.2^{\circ}-16.8^{\circ}$, and gain of $12.0-$ $15.2 \mathrm{~dB}$ for all scanning angles (up to $40^{\circ}$ ). The sidelobe levels can be further reduced by using a sharper tapered excitation, which, however, could complicate the realization more.

3.3. Measurements of Low-Sidelobe Arrays. In order to verify the low-sidelobe performances, two eight-element linear arrays with $0^{\circ}$ and $40^{\circ}$ fixed-scan angles were designed, fabricated, and measured with the cavity-backed angleddipole antenna having a center-to-center spacing of $5.6 \mathrm{~mm}$ $\left(0.52 \lambda_{28-\mathrm{GHz}}\right)$. The tapered excitation shown in Figure 6(a) was used for both arrays. To realize the tapered excitation, unequal T-junction power dividers were used for the feeding network. Figure 7 shows the basic design of an unequal T-junction power divider. Standard quarterwavelength and tapering transformers were employed to achieve the impedance matching. Figure 8(a) shows fabricated sample of the array with $0^{\circ}$ scan angle. Its feeding network was realized through a number of T-junction power dividers (shown in Figure 7) and optimized to achieve the tapered distribution and in-phase at the outputs. The simulated and measured $\left|S_{11}\right|$ of the array are illustrated in Figure $8(\mathrm{~b})$. Both simulation and measurement resulted in a good impedance matching $\left(\left|S_{11}\right|<-10 \mathrm{~dB}\right)$ at $27-30 \mathrm{GHz}$. Figure $8(\mathrm{c})$ shows the $28 \mathrm{GHz}$ radiation pattern of the $0^{\circ}$ scan angle array. There is a good agreement between the simulated and measured results. For the $E$-plane pattern, both measurement and simulation resulted in an HPBW of $15^{\circ}$ and a sidelobe level of $<-23 \mathrm{~dB}$. These results also agreed well with the theoretical values obtained by the array-factor (Figure 6(c)). In addition, the $H$-plane pattern of the array was similar to the single element pattern with an HPBW of $\sim 70^{\circ}$.

Figure 9 (a) shows fabricated sample of the array with $40^{\circ}$ scan angle. Its feeding network employed several unequal T-junction power dividers (shown in Figure 7) and fixed microstrip line delays to achieve the desired powers and phases at the outputs. Moreover, the unequal dividers were used to compensate the microstrip line loss in the delay lines. As shown in Figure 9(b), both simulation and measurement yielded a $\left|S_{11}\right|<-10 \mathrm{~dB}$ at $26-30 \mathrm{GHz}$. Figure 9(c) shows the $28 \mathrm{GHz}$ pattern in $E$-plane for the fabricated array with $40^{\circ}$ scan angle. The measurements agreed well with the simulations and both resulted in a sidelobe level below $-15 \mathrm{~dB}$ and an HPBW of $18^{\circ}$. Due to the imperfect feeding network, the measurements resulted in a grating lobe below $-12 \mathrm{~dB}$ in comparison to the simulated value of below $-15 \mathrm{~dB}$.

Table 1 shows a summary for the gain of the eightelement linear arrays obtained by array-factor, simulation, and measurement. Due to the undesired losses of the feeding networks, the gains of realized array are less than the theoretical values obtained by the array-factor function of CST Microwave Studio. However, there is only a slight difference between the measured and simulated gains of the fabricated arrays.

\section{Conclusion}

A cavity-backed angled-dipole antenna and its arrays have been presented for the $28 \mathrm{GHz}$ millimeter-wave wireless 

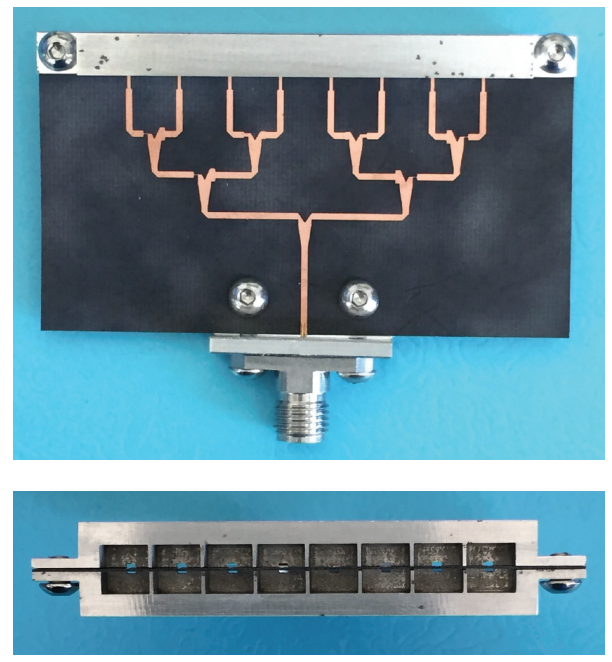

(a)

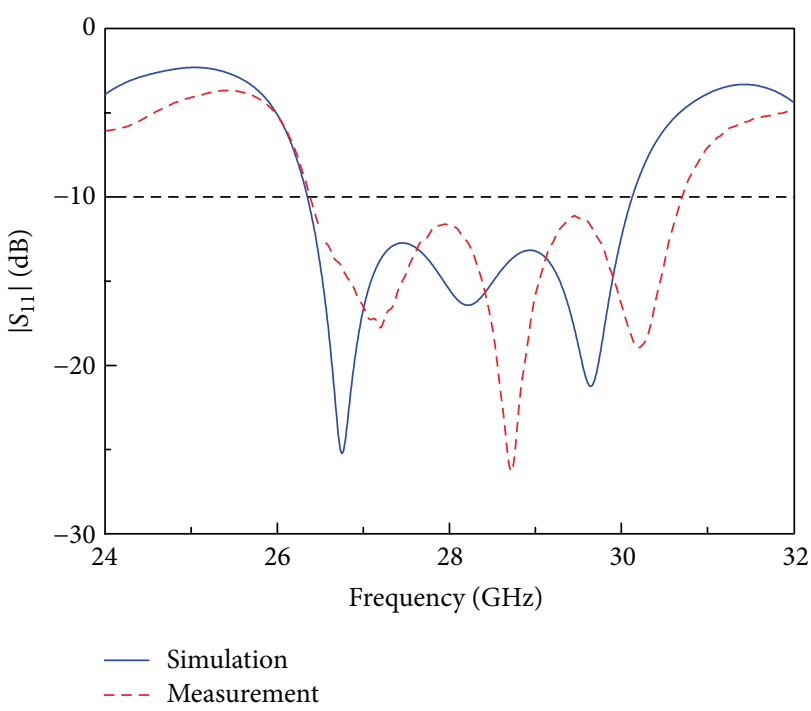

(b)

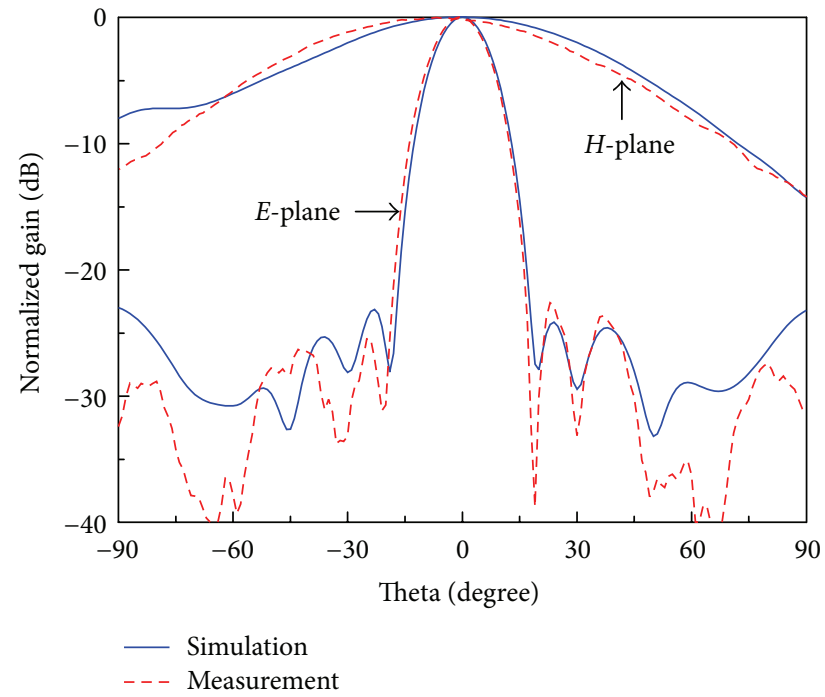

(c)

Figure 8: (a) Fabricated sample of the eight-element array with $0^{\circ}$ scan angle: its (b) $\left|S_{11}\right|$ values and (c) normalized $28 \mathrm{GHz}$ pattern.

applications. Because of the use of the cavity, the radiation characteristics of the angled dipole-including gain, back radiation, pattern profile, and similar beamwidth in the $E$ and $H$-planes-are significantly enhanced. The design with cavity aperture of $5.2 \mathrm{~mm} \times 5.2 \mathrm{~mm}\left(0.5 \lambda_{28-\mathrm{GHz}} \times 0.5 \lambda_{28-\mathrm{GHz}}\right)$ yields a broadband operation $(26.7-30.6 \mathrm{GHz})$, a small gain variation $(6.6-8.0 \mathrm{~dB})$, and similar HPBW in the $E$ - and $H$-planes $\left(\sim 70^{\circ}\right)$. By using nonuniform power distribution across the excitations, the eight-element linear arrays with cavity-backed angled-dipole antenna having a center-tocenter spacing of $5.6 \mathrm{~mm}\left(0.52 \lambda_{28-\mathrm{GHz}}\right)$ achieved scan angle up to $40^{\circ}$ and sidelobe below $-15 \mathrm{~dB}$. For verification, two linear arrays of $0^{\circ}$ and $40^{\circ}$ scan angles were fabricated and measured. The fabricated arrays achieve a sidelobe level below $-23 \mathrm{~dB}$ and $-15 \mathrm{~dB}$ for the $0^{\circ}$ and $40^{\circ}$ scan angle arrays, respectively. These results indicate that the cavity-backed angle-dipole antenna and its arrays are good candidates for use in the antenna sectors of the future 5G millimeter-wave cellular wireless networks as well as other millimeter-wave wireless communication systems.

\section{Competing Interests}

The authors declare that there are no competing interests regarding the publication of this paper.

\section{Acknowledgments}

This work was supported by the ICT R\&D Program of MSIP/IITP [14-911-01-001]. 


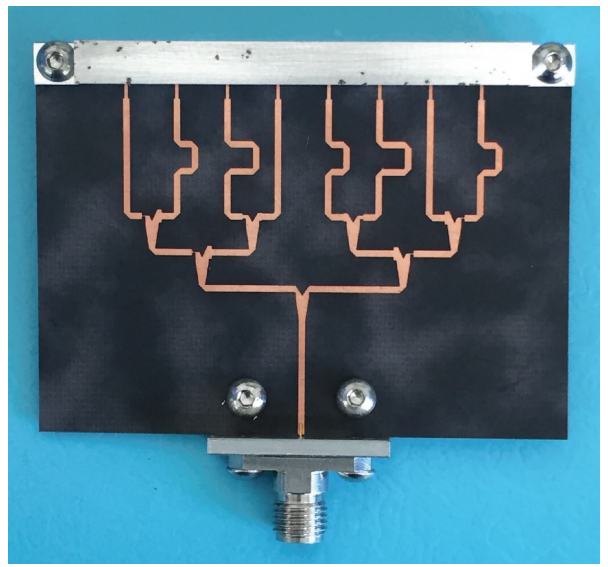

(a)

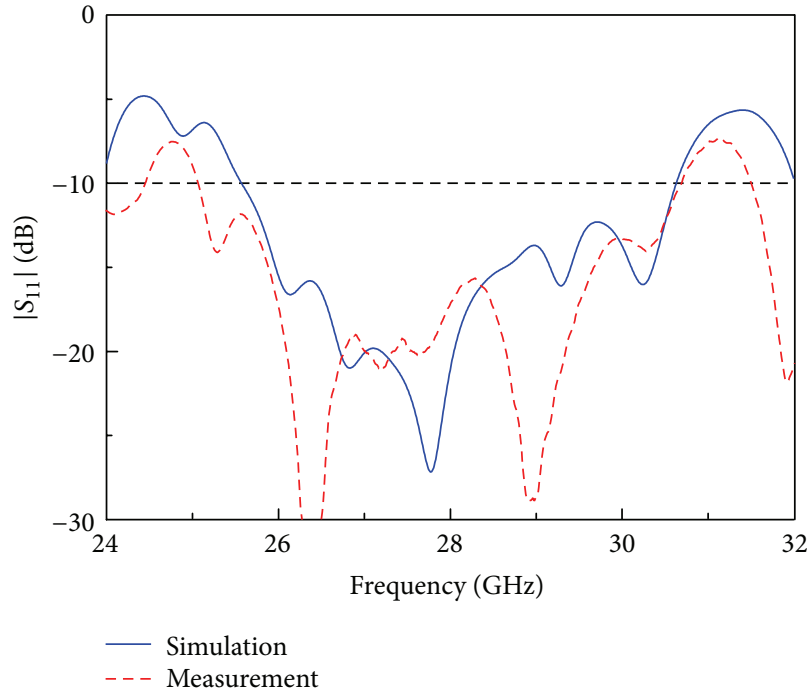

(b)

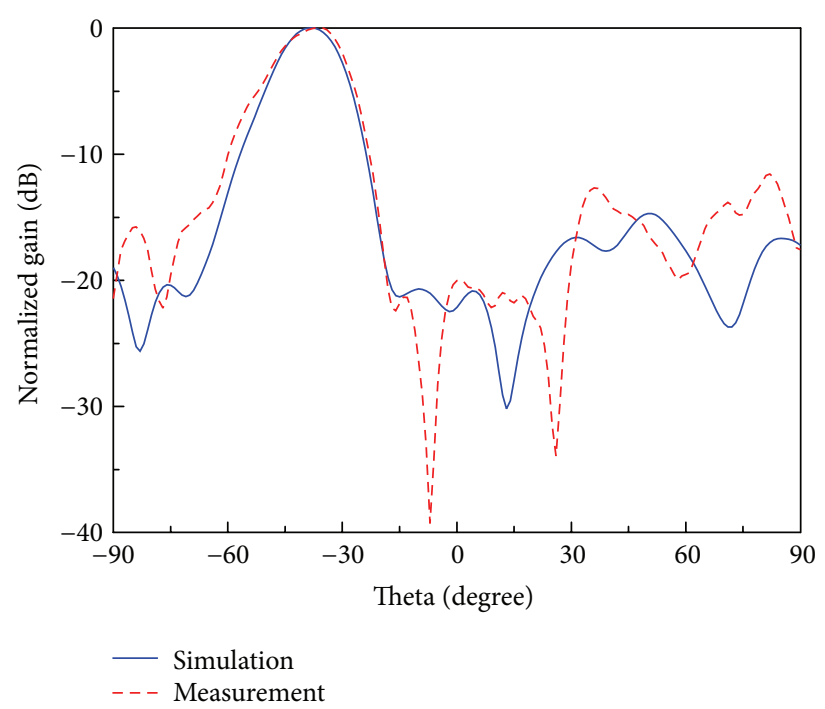

(c)

Figure 9: (a) Fabricated sample of the eight-element array with $40^{\circ}$ scan angle; its simulation and measurement (b) $\left|S_{11}\right|$ values and (c) normalized $28 \mathrm{GHz}$ pattern in $E$-plane.

\section{References}

[1] T. S. Rappaport, S. Sun, R. Mayzus et al., "Millimeter wave mobile communications for $5 \mathrm{G}$ cellular: it will work!", IEEE Access, vol. 1, pp. 335-349, 2013.

[2] S. Rangan, T. S. Rappaport, and E. Erkip, "Millimeter-wave cellular wireless networks: potentials and challenges," Proceedings of the IEEE, vol. 102, no. 3, pp. 366-385, 2014.

[3] W. Roh, J.-Y. Seol, J. Park et al., "Millimeter-wave beamforming as an enabling technology for $5 \mathrm{G}$ cellular communications: theoretical feasibility and prototype results," IEEE Communications Magazine, vol. 52, no. 2, pp. 106-113, 2014.

[4] S. M. Razavizadeh, M. Ahn, and I. Lee, "Three-dimensional beamforming: a new enabling technology for 5G wireless networks,' IEEE Signal Processing Magazine, vol. 31, no. 6, pp. 94-101, 2014.

[5] D. Parker and D. C. Zimmermann, "Phased arrays-part I: theory and architectures," IEEE Transactions on Microwave Theory and Techniques, vol. 50, no. 3, pp. 678-687, 2002.
[6] D. Parker and D. C. Zimmermann, "Phased arrays-part II: implementations, applications, and future trends," IEEE Transactions on Microwave Theory and Techniques, vol. 50, no. 3, pp. 688-698, 2002.

[7] Y.-H. Suh and K. Chang, "A new millimeter-wave printed dipole phased array antenna using microstrip-fed coplanar stripline Tee junctions," IEEE Transactions on Antennas and Propagation, vol. 52, no. 8, pp. 2019-2026, 2004.

[8] J. Xu and W. Dou, "Application of novel printed dipole antenna to design broadband planar phased array," International Journal of Antennas and Propagation, vol. 2014, Article ID 946763, 5 pages, 2014.

[9] R. A. Alhalabi and G. M. Rebeiz, "High-efficiency angled-dipole antennas for millimeter-wave phased array applications," IEEE Transactions on Antennas and Propagation, vol. 56, no. 10, pp. 3136-3142, 2008.

[10] P. Knott, "Design of a printed dipole antenna array for a passive radar system," International Journal of Antennas and Propagation, vol. 2013, Article ID 179296, 6 pages, 2013. 
[11] S. X. Ta and I. Park, "A cavity-backed angled-dipole antenna array for low millimeter-wave bands," in Proceedings of the International Workshop on Antenna Technology (iWAT '16), pp. 57-59, Cocoa Beach, Fla, USA, Feburary 2016.

[12] Q. Jiang and S.-W. Qu, "Novel multiport cavity-backed antenna for low-cost array applications," IEEE Antennas and Wireless Propagation Letters, vol. 14, pp. 1419-1422, 2015.

[13] D. M. Pozar, "Active element pattern," IEEE Transactions on Antennas and Propagation, vol. 42, no. 8, pp. 1176-1178, 1994.

[14] E. C. DuFort, "Optimum low sidelobe high crossover multiple beam antennas," IEEE Transactions on Antennas and Propagation, vol. AP-33, no. 9, pp. 946-954, 1985. 


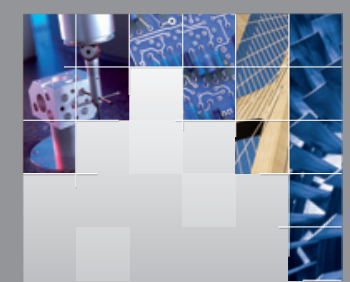

\section{Enfincering}
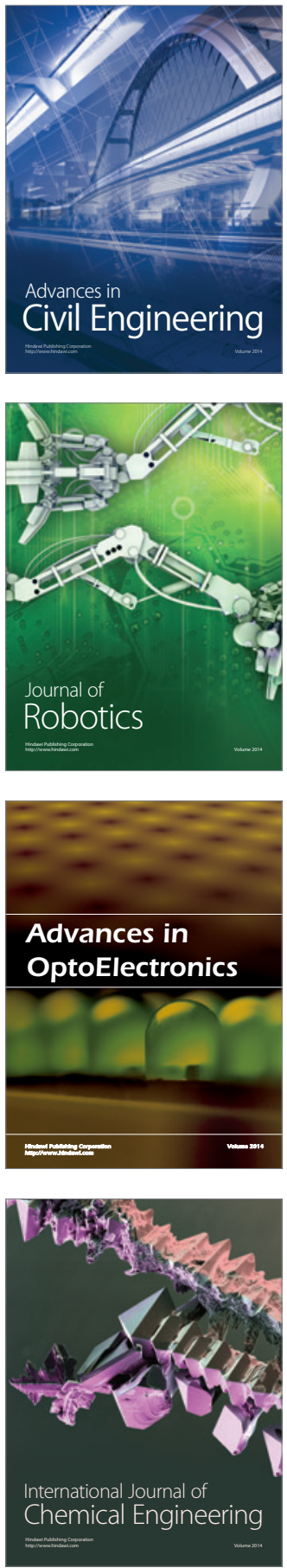

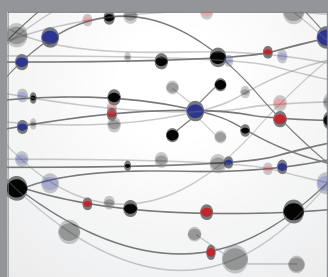

The Scientific World Journal

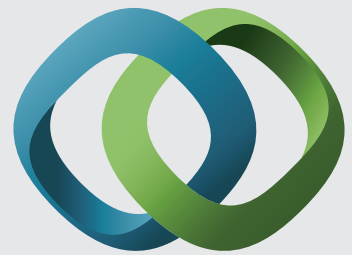

\section{Hindawi}

Submit your manuscripts at

http://www.hindawi.com
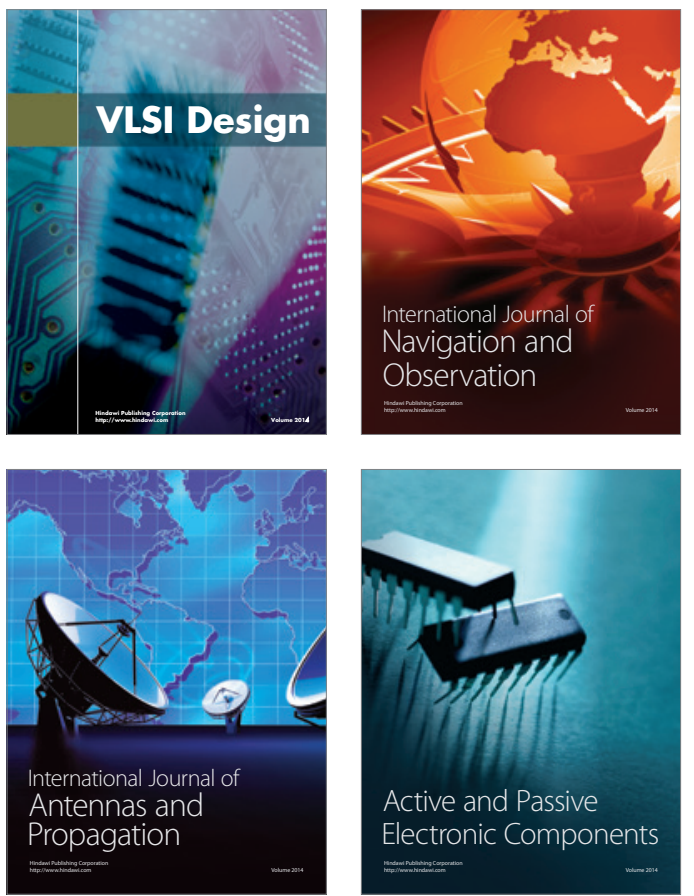
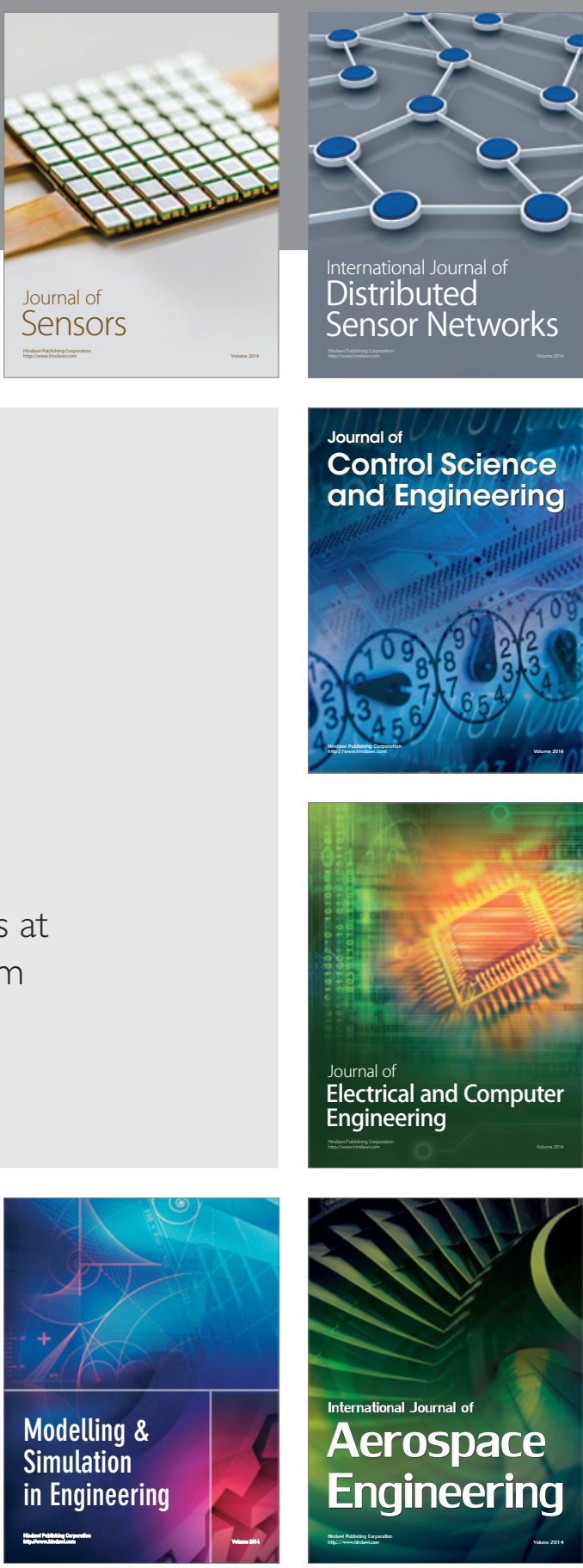

International Journal of

Distributed

Sensor Networks

Journal of

Control Science

and Engineering
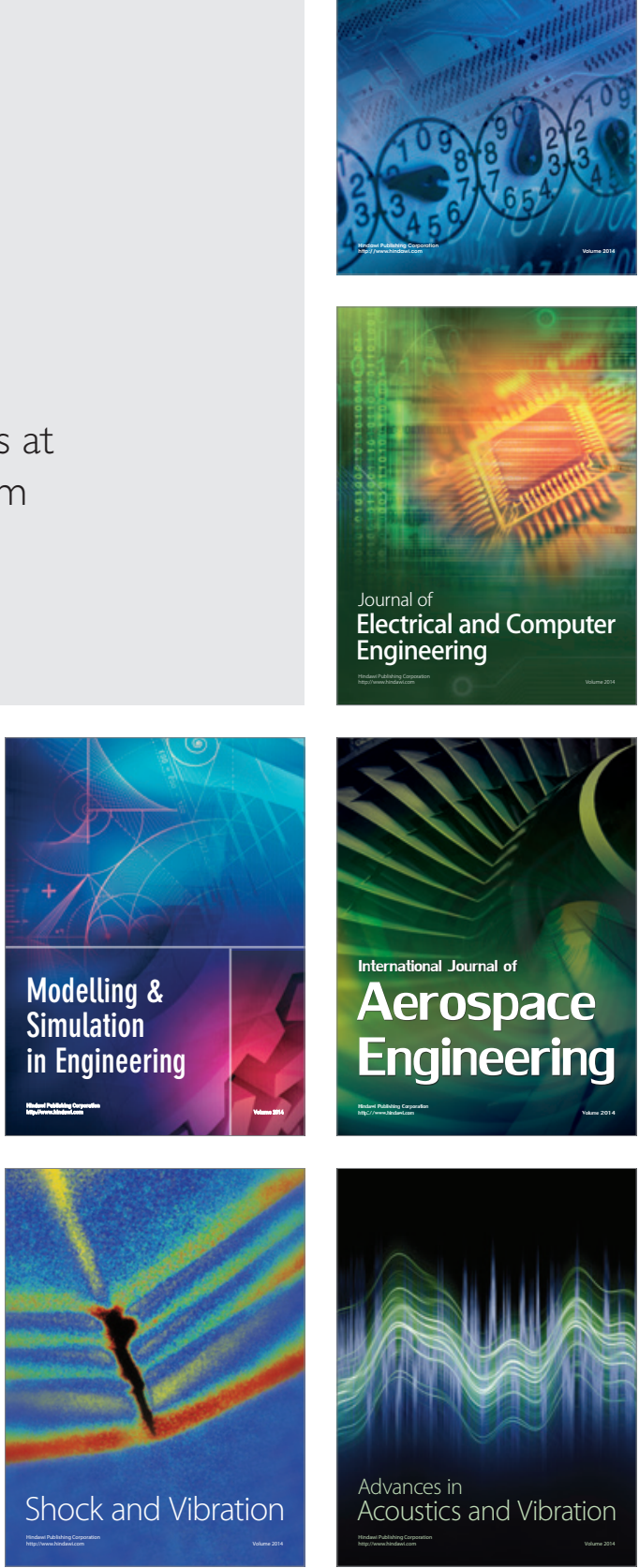